\title{
Is Sensation Seeking Linked Only to Personality Traits? The Role of Quality of Attachment in the Development of Sensation Seeking among Italian Adolescents: A Longitudinal Perspective
}

Ugo Pace

\author{
Carmela Madonia
}

Alessia Passanisi

Calogero lacolino

University Kore of Enna

\section{Rosanna Di Maggio}

University of Palermo

\section{Doi:10.5901/mjss.2015.v6n2s1p260}

\begin{abstract}
Considering sensation seeking as a personality trait has led to the driving of a series of studies on the biological and temperamental characteristics of sensation seekers. Conversely, from a bio-psychosocial perspective, personality factors are believed to account for about half of the likelihood that an individual will engage in disadaptive and dangerous actions, whereas environmental factors, such as primary relationships, interact with the person's biology and affect the extent to which genetic factors exert their influence. On the light of these considerations, the present study explored the unique and common contributions of temperament and quality of attachment measured from 15 years old through the propensity of sensation seeking at 17 years old. The research involved 320 participant, from 14 to 16 years of age at wave 1, and 282 (16 to 18 years, $88 \%$ of the total sample) at wave 2. Data showed that negative affect at T1 emerged as a significant positive predictor of sensation seeking at T2. Moreover, dismissing attachment at T1 was positively related to thrill seeking at T2. Finally, dismissing attachment at T1 played a mediating role in the relationships between negative affect and lack of control and thrill seeking two years later. Starting from the results of the present study, treatment of adolescent in which sensation seeking may be seen as predictive of problematic behaviors may be based on the reorganization of the personal model of attachment.
\end{abstract}

Keywords: adolescence, sensation seeking, temperament, attachment

\section{Introduction}

Findings of recent studies on risky behaviors have shown a reliable link between high sensation-seeking behavior and engagement in risk-taking behaviors during adolescence (Zuckerman, 2007). Zuckerman (1994) defined sensation seeking as "the seeking of varied, novel, complex, and intense sensations and experiences, and the willingness to take physical, social, legal, and financial risks for the sake of such experience" (p. 27).

An increasing number of adolescents and young people are fascinated by intense stimuli and strong sensations (VV.AA., Eurispes, 2012). Many of them seem to develop a sort of insensitivity to the gratification of the everyday life events. The threshold of gratification becomes increasingly higher, the low capacity for pleasure makes many young apathetic, bored or incapable to be able to defer the achievement of the desires.

Sensation-seekers are characterized by low sensitivity to stimuli and therefore in need of high levels of stimulation to maintain an optimal state of arousal. To the extent that individuals need sensations, they engage in behavior that increases the amount of stimulation they experience, and they are likely to take risks to that end. Data have indeed highlighted that high sensation-seekers report significant levels of violent behavior (Lynne-Landsman et al., 2011; Pace et al., 2013), abuse of illegal substance, alcohol use and risky sexual behaviors (Baiocco et al., 2009; Laghi et al., 2013).

Although it seems clear the predictor role of sensation seeking in risky behavior in adolescence appears to be less clear the complex dynamics related to personal and social development that can be identified as predictors of this need of 
extreme sensations. In other words, considering sensation seeking as a personality trait, in recent years, has led to the driving of a series of studies on the biological and temperamental characteristics of sensation seekers (Sijtsema et al., 2010). In this sense, this personality trait has been described by Zuckerman in his work on biopsychological personality research and is often related to biochemical reactions in the brain (Steinberg, 2008). Within this conceptual framework, recent studies have underlined that changes in sensation seeking during adolescent development have been hypothesized to be due to maturational changes in the adolescent brain (Somerville et al., 2010). The authors highlighted that subcortical brain regions involved in responding to novel, rewarding, or emotional stimuli, such as amygdala and nucleus accumbens, "show an exaggerated response profile in adolescents" (p. 131). According to this neurodevelopmental model (Ernst et al., 2006), risk-taking and delinquent behavior are due to the rapid increases in sensitivity to high sensation seeking that occur and to the contemporary slow maturation of cortical structures that govern inhibition, planning, and executive control during adolescent development.

Conversely, from a transactional perspective, developmental trajectories are changeable, and the outcomes are linked to several protective and risk factors, such as the quality of early relationships, the way to deal with development tasks, and the ability to take advantage of social networks (Rutter, 2007). As far as problematic behavior is concerned, from a bio-psychosocial perspective, personality factors are believed to account for about half of the likelihood that an individual will engage in disadaptive and dangerous actions, whereas environmental factors interact with the person's biology and affect the extent to which genetic factors exert their influence (Agrawal and Lynskey, 2008; Guzzo et al., 2013). As far as the involvement of personality traits, as Rutter (1987) underlined, temperament shapes personality development and influences developmental outcomes. Temperament has been defined as "biologically rooted individual differences in behavior tendencies that are present early in life and are relatively stable across various kinds of situations and over the course of time" (Bates 1987, p. 1101). In particular, Rothbart and Derryberry (1981) defined temperament as individual differences in reactivity, the responsivity of the behavioral and psychological system, and self-regulation-this is the neural process that modulates reactivity and is assumed to have a constitutional basis. Temperament is believed to play an important role in children and adolescents' social and personality development, psychological adjustment, and different forms of addictions (Pace et al., 2014). For example, a controlled temperamental nature could inhibit positive and negative responses depending on the trends of subdominant response. Studies on the relationships between temperament and sensation seeking have noted that some temperamental or dispositional factors such as impulsivity or disinhibition are linked with adolescents' risk-taking (Harden et al., 2012).

Recently, adolescent maladjustment has been explained in the light of the difficulties of the subject to face typical developmental tasks characterizing this phase of life (Steinberg, 2002). From a nondeterministic perspective, variables predisposing an issue of conduct as the frantic search for excessive stimuli need to be considered in continuous relationship with other factors. Among these, the conception of self and others and the basis of primary bonds as revealed in tasks regarding attachment could be considered tools in the analysis of the onset of several potential pathological behaviors (e.g., Rutter, 2007; Schimmenti et al., 2013; Schimmenti et al., 2014).

The exploration of an increasing number of psychosocial factors that may moderate or mediate the transition from conducting an activity to get pleasure (such as the research of a novelty or an interesting activity) to the compulsive need to fulfill an urge that impairs daily functioning negatively through thrilling or dangerous actions, may allow us to distinguish adaptive and disadaptive behaviors. Researchers have highlighted the role that quality of attachment, resulting from the parent-child attachment bond, may play in the adaptive or maladaptive course of development throughout adolescence (Allen et al., 1996; Armsden and Greenberg, 1987; Cacioppo, Pace and Zappulla, 2013). While a high quality of attachment (security) seems to protect from the onset of general disorders during adolescence (Leadbeater et al., 1999; Schimmenti et al., 2012), a low quality of attachment (insecurity) can be considered just as predictive of adolescents' problem behaviors (Laible et al., 2000; Pace and Zappulla, 2011; Pace et al., 2012).

\section{Objectives of the Present Study}

Starting from the controversial findings concerning the role of personality traits and primary relationships in increasing (or, conversely, buffering) psychological disadvantage during the developmental trajectory, the study explored the unique and common contributions of temperament and quality of attachment measured from 15 years old through the propensity of sensation seeking (a trait considered predictive of risk behaviors) at 17 years old. Regarding the unique contributions of temperament, we hypothesized that the dimension of control during the first step of adolescence would primarily correlate with middle adolescents' propensity to need risk sensations. Moreover, an inadequate level of attachment at 15 years old would also be predictive of sensation seeking. In terms of joint contribution of temperamental traits and attachment, we hypothesized that insecure attachment may be a mediating variable in the relationship between temperament and 
sensation seeking; in this sense, the main objective of the present study was to better understand the known relationship between temperamental traits and sensation seeking by exploring the potential underlying process linking to the attachment system. If hypothesis of the present study will be confirmed, sensation seeking wouldn't be simply seen as part of personality but as related to quality of internal working models; as consequences, it could be designed psychological path based on the new symbolization of other and self, for adolescents in which seeking of intense sensations and experiences may lead to physical or psychological risks.

\section{Method}

\subsection{Participants}

Students from four high schools from different parts of Italy took part in this two wave longitudinal study. The choice of using the longitudinal method is due to the objectives of the study, for which adolescent development is seen as a development instead of a simple relation among variables. The current study is based on 320 participant, from 14 to 16 years of age at Time 1 ( 165 boys and 155 girls; $M=15.10$; $S D=.83$ ). The overall participation rate $88 \%$ across the two waves; nonparticipation was due to student absenteeism. Participants at Time 2 were 282 pupils (143 boys and 139 girls) from 16 to 18 years of age ( $M=17.23$; SD = .93). In terms of type of high school, $24 \%$ of students were enrolled in scientific focused schools, $33 \%$ were in technical-industrial arts schools, and $43 \%$ were in classic studies schools. All the participants were Italian. To recruit participants, we employed a 'passive' consent procedure (i.e., informing the parents in advance about the nature of the study and providing the opportunity for the parents to call our research office if they did not want their child participating in the study). We sent letters to the parents of the students in the target classes informing them of the nature of the study. We provided an opportunity to contact the child's school or our office about the project. There were no parents that objected to involvement of their child in the study. We obtained the assent from all the adolescents involved in the study.

\subsection{Measures}

Temperament. We administered the Adult Temperament Questionnaire-Short Form (ATQSF; Rothbart 2006; Evans and Rothbart, 2007), a self-report questionnaire that assesses general constructs underlying individual's temperament. The measure consisted of 77 items to which adolescents could answer on a 7-point Likert scale ranging from 1 (extremely untrue) to 7 (extremely true) and allowed obtaining information on 13 sub-constructs belonging to four general constructs: Negative Affect [subconstructs: Fear (e.g. "I become easily frightened"), Frustration (e.g. "Whenever I have to sit and wait for something (e.g., a waiting room), I become agitated"), Sadness (e.g., "I often feel sad"), and Discomfort (e.g. "I find certain scratchy sounds very irritating")]; Extraversion/Surgency [subconstructs: Sociability (e.g., "I usually like to talk a lot"), High Intensity Pleasure (e.g., "When listening to music, I usually like turn up the volume more than other people"), and Positive Affect (e.g. "Sometimes minor events cause me to feel intense happiness"]; Orienting Sensitivity [subconstructs: Neutral Perceptual Sensitivity (e.g., "I'm often aware of the sounds of birds in my vicinity"), Affective Perceptual Sensitivity (e.g., "I tend to notice emotional aspects of paintings and pictures"), and Associative Sensitivity (e.g. "I sometimes seem to understand things intuitively"]; Lack of Control [subconstructs: Activation Control (e.g., "I often make plans that I do not follow through with"), Attentional Control (e.g., "It's often hard for me to alternate between two different tasks"), and Inhibitory Control (e.g. "I usually have trouble resisting my cravings for food drink, etc."]. Originally, the latter construct (Lack of Control) was in a positive direction and was called Effortful Control. For the present study we decided to use the construct in its negative value in order to better focus on temperamental difficulties related to sensation seeking. A confirmatory factor analysis of data from the current study confirmed the original structure with four factors, Negative Affect $(\alpha=0.78)$, Extraversion/Surgency $(\alpha=0.72)$, Orienting Sensitivity $(\alpha=0.80)$, and Low Control $(\alpha=0.77)$.

Attachment. We administered the Relationship Questionnaire (RQ; Bartholomew and Horowitz 1991), a short instrument containing multi-sentence descriptions of each of four attachment styles: (a) Secure ("It is easy for me to become emotionally close to others. I am comfortable depending on them and having them depending on me. I don't worry about being alone of having others non accept me"); (b) Dismissing ("I am comfortable without close emotional relationships. It is very important to me to feel independent and self sufficient, and I prefer not to depend on others or have others depend on me"); (c) Preoccupied ("I want to be completely emotionally intimate with others, but I often find that others are reluctant to get as close as I would like. I am uncomfortable being without close relationships, but I sometimes worry that others don't value me as much as I value them"); (d) Fearful ("I am uncomfortable getting close to 
others. I want emotionally close relationships, but I find it difficulty to trust others completely, or to depend on them. I worry that I will be hurt if I allow myself to become too close to others"). Adolescents were asked to choose the description that best characterized them and then to rate each description according to how well it described them, on a 7-point Likert scale ranging from 1 (not at all like me) to 7 (completely like me). The choice of the description allowed to assign each individual to an attachment category. The rating of how well each description described each participant allowed to obtain a score for each attachment style.

Sensation Seeking. The Italian version of the Zuckerman Sensation Seeking Scale-Form V (SSS-V) was used as a measure of sensation seeking (Galeazzi et al., 2003). There are four subscales of the SSS-V, which include: boredom susceptibility (BS), experience seeking (ES), disinhibition (DIS), and thrill seeking (TS). Each subscale includes a series of ten questions resulting in 40 items for the full SSS. A review of all of the available published data on the internal consistency reliability ( $a$ ) of the SSS-V found that the mean reliabilities were $a=0.62$ for $B S, a=0.69$ for $E S, a=0.69$ for DIS, and $a=0.75$ for TAS (Deditius-Island and Caruso 2002); the authors noted the particularly low reliability of the BS scale. In the present study the internal consistency reliabilities were $a=0.55$ for $B S, a=0.61$ for ES, $a=0.73$ for DIS, and $\mathrm{a}=0.80$ for TS. Consistent with the review of previous studies, the reliability of the boredom susceptibility scale was also low in the present study. Scores on subscales with 1-3 missing items were pro-rated based on responses to the remaining non-missing items.

\section{Results}

Analysis plan. Pearson's $r$ correlations were computed in order to investigate the associations between temperament and attachment variables at T1 and sensation seeking variables at T2. Correlational analyses were used to explore the associations between temperament, attachment and sensation seeking. Linear regression analyses were carried out to explore the contribution of temperament and attachment scores in predicting sensation seeking, and finally, to examine whether quality of attachment mediated the relationship between temperament and level of sensation seeking, we used traditional methods of testing mediation, including Baron and Kenny's four-step approach to mediation (Baron and Kenny, 1986) and the Sobel's test (Sobel, 1982), as well as a bootstrapping method with bias-corrected confidence intervals (Preacher and Hayes, 2004) to further investigate the significance of these mediation effects. According to Baron and Kenny, mediation occurs when the following conditions are respected: (a) the independent variable (in our case, temperament) significantly predicts the mediator variable (in our case, attachment); (b) the mediator variable significantly predicts the dependent variable (in our case, sensation seeking); (c) when the effects of the mediator are controlled for, a previously significant predictive association between the independent variable and the dependent variable becomes non significant. Sobel's z test provides a method to determine whether the reduction in the effect of the independent variable, after including the mediator in the model, is a significant reduction and therefore whether the mediation effect is statistically significant. Bootstrapping is a nonparametric approach to hypothesis testing, estimating the standard errors empirically using the available data. It does not impose the assumption of normality of the sampling distribution. Multiple samples (with replacement) are drawn from the original data set and the model is re-estimated on each sample.

Tab 1. Correlations between temperament, attachment and sensation seeking

\begin{tabular}{|c|c|c|c|c|c|c|c|c|c|c|c|c|}
\hline & $\begin{array}{c}1 \\
\mathrm{NA}\end{array}$ & $\begin{array}{l}2 \\
E\end{array}$ & $\begin{array}{c}3 \\
\text { Sen }\end{array}$ & $\begin{array}{c}4 \\
\text { LoC }\end{array}$ & $\begin{array}{c}5 \\
\text { Sec }\end{array}$ & $\begin{array}{l}6 \\
D \\
\end{array}$ & $\begin{array}{l}7 \\
P \\
\end{array}$ & $\begin{array}{l}8 \\
F\end{array}$ & $\begin{array}{c}9 \\
\text { BS }\end{array}$ & $\begin{array}{l}10 \\
\text { ES }\end{array}$ & $\begin{array}{l}11 \\
D\end{array}$ & $\begin{array}{l}12 \\
\text { TS }\end{array}$ \\
\hline 1. Negative Affect T1 & 1 & & & & & & & & & & & \\
\hline 2. Extraversion $\mathrm{T} 1$ & $-.27^{\star \star}$ & 1 & & & & & & & & & & \\
\hline 3. Sensitivity T1 & $.21^{\star}$ & .11 & I & & & & & & & & & \\
\hline 4. Lack of Control T1 & $.38^{\star \star}$ & $-.18 *$ & $.17^{\star}$ & I & & & & & & & & \\
\hline 5. Secure T1 & $-.23^{*}$ & .08 & -.09 & $-.30^{* \star}$ & I & & & & & & & \\
\hline 6. Dismissing T1 & $.28^{\star \star}$ & .11 & .11 & $.29 * *$ & $-.28^{\star \star}$ & I & & & & & & \\
\hline 7. Preoccupied T1 & .14 & .02 & .13 & .12 & $-.20^{*}$ & $.23^{*}$ & l & & & & & \\
\hline 8. Fearful T1 & .10 & -.10 & $.18^{*}$ & .09 & -.11 & .09 & $.16^{*}$ & 1 & & & & \\
\hline 9. Boredom susceptibility T2 & .11 & .12 & $.22^{*}$ & $.21 *$ & .03 & .11 & .12 & -.13 & 1 & & & \\
\hline 10. Experience seeking T2 & .14 & .09 & .13 & .03 & .10 & .07 & .09 & -.09 & $-.19 *$ & I & & \\
\hline 11. Disinhibition T2 & .13 & .11 & .11 & .12 & $-.19 *$ & .08 & $.19^{*}$ & .11 & $.23^{*}$ & $.19 *$ & 1 & \\
\hline 12. Thrill seeking $T 2$ & $.31^{\star \star}$ & -.06 & .11 & $.37^{\star *}$ & -.15 & $.39 * *$ & .10 & .04 & $.32^{\star \star}$ & $.29 * *$ & $.33^{\star *}$ & 1 \\
\hline
\end{tabular}

${ }^{*} p<.05 ;{ }^{*} p<.01$ 
As predicted (Table 1), significant associations were found between temperament variables at T1 (Negative Affect and Lack of Control) and a sensation seeking factor (Thrill seeking) at T2; between temperament variables at T1 (Negative Affect and Lack of Control) and attachment at T1 (Secure and Dismissing); between attachment variable T1 (dismissing and secure) and a sensation seeking factor at T2 (Thrilling seeking). Linear regression analyses were performed to look at the unique contribution given by temperament variables in the prediction of attachment scores and sensation seeking scores. Results of the regression analyses showed that Negative Affect at T1 was a significant predictor of attachment scales scores at $T 1$, particularly secure $(\beta=-.19, p<.001)$ and dismissing $(\beta=.20, p<.001)$. As sensation seeking was concerned, the results showed predictive associations between Negative Affect and Lack of control at T1 and Thrilling Seeking at T2 (respectively $\beta=.22, p<.001$ and $\beta=.24, p<.001$ ), and predictive associations between dismissing attachment at $\mathrm{T} 1$ and thrilling seeking $\mathrm{T} 2(\beta=.21, p<.001)$.

Finally, we tested whether dismissing scores mediated the relationship between Negative affect and sensation seeking scores in the overall sample. Results of the mediation studies are shown in Table 2.

Table 2. Results of mediation analyses with Negative affect and Lack of Control as predictors at T1, Thrilling seeking as outcomes at $\mathrm{T} 2$, and dismissing attachment as mediating variable at $\mathrm{T} 1$

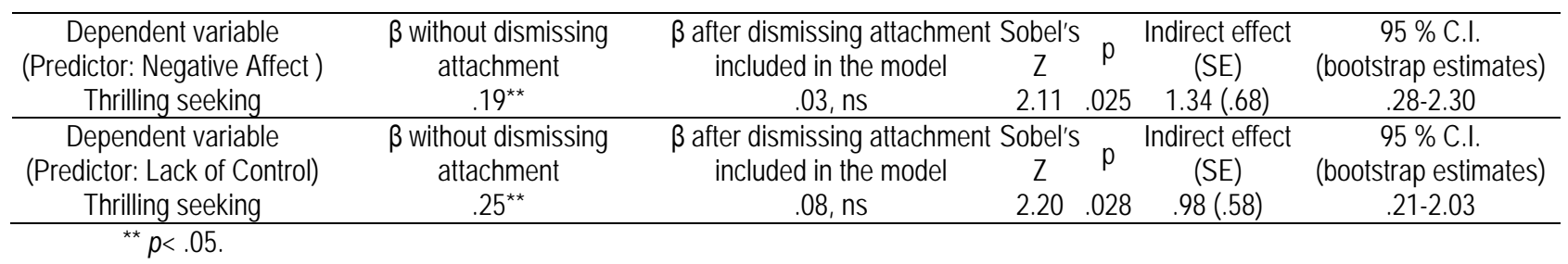

As showed, Dismissing attachment scores mediated at T1the effects of Negative affect and Lack of control at T1 on Thrilling Seeking at T2. In fact, Negative affect and Lack of control were significant predictors of thrilling seeking scales scores, but these predictive associations became non significant after controlling for dismissing attachment scores. Moreover, findings from the Sobel's test and bootstrapping analyses showed that the total indirect effects of Negative affect and Lack of Control on all the thrilling seeking scores through dismissing attachment scores were significant, thus these variables totally mediated the relationship between temperamental negative affect and the need of thrilling seeking in this sample. Therefore, results of mediation analyses suggest that dismissing attachment might play a crucial role in linking temperamental features and sensation seeking in adolescence.

\section{Discussion}

The purpose of this study was to examine the role played by temperamental traits and quality of attachment in sensation seeking during adolescent development, focusing on the unique and common contributions of the different independent variables. In the present study, as expected, results showed that both temperament and quality of attachment measured at 15 years old were related to adolescents' sensation seeking as middle adolescents measured at 17 years old; the data suggested that some of these dimensions could be considered as risk factors because negative affect, lack of control, and dismissing attachment were positively related to thrill seeking.

Data highlighted that dismissing attachment at T1 may play a mediating role in the relationships between negative affect and lack of control and thrill seeking two years later.

As far as the contribution of temperament, negative affect at $\mathrm{T} 1$ emerged as a significant positive predictor of sensation seeking at T2. The results confirmed the role of temperament found in literature. As previously highlighted, temperament plays a relevant role in the development of emotion regulation strategies, dysfunctional personality traits, and risky behaviors (e.g., Rothbart et al. 2000). Temperamental traits included a negative quality of affectivity and a low level of emotional and behavioral control and were associated with sensation and novelty-seeking (Putnam et al. 2001); they also predict less moral behavior and guilt (Kochanska and Aksan, 2006) and less sensitivity to punishment (Dadds and Salmon, 2003; Prinzie et al., 2004) in adolescents. Our prediction of dismissing attachment's role in sensation seeking was consistent with that of Sarracino et al. (2011), who noted that especially in girls, sensation seeking is positively associated with a negative model of others. Especially during adolescence, the excessive seeking of strong sensations can easily lead to compulsive behaviors if some predisposing personal and contextual factors are present. Secure attachment with caregivers could protect adolescents from dysfunctional behaviors, diminishing their sensation 
seeking (Barnea et al., 1992), whereas insecure adolescents may have learned to consider interdependent situations and partners as threatening and risky, developing competitive and individualistic behavioral models and a greater risk-taking tendency. Adolescents characterized by insecure attachment may not have any resource that may make sense for them. Since they cannot find either in himself or in contact with others that exchange essential to well-being, they may replace it with what is possible and always available: self-stimulation of their emotions. In this sense, these individuals, tend to substitute an attachment relationship with physical sensations, potentially self-destructive (Jeammet, 2008).

Research linking temperament and attachment has shown that children who display high levels of negative emotionality affect the parents' perceived abilities to help them in managing affect, which in turn promotes the children's aggressive behavior patterns (Eisenberg et al., 2008), leading to a continuous cycle of conflict that challenges the construction of secure attachment bonds (Rothbart, 1986). On the contrary, lower child emotional negativity and greater attachment security have been shown to be associated with higher levels of parent responsiveness (Rispoli et al., 2013). Some have hypothesized that temperamental differences in infants affect the development of infant-mother interactions and, thus, the mother-infant attachment relationship (Belsky and Rovine, 1987; Buss and Plomin, 1984). The temperamental dimension of low control or the expression of negative affect have been shown to influence the quality of mother-infant interaction. Associations between infant irritability and maternal behavior have been investigated using different measures of irritability. Furthermore, according to Caspi et al. (1997), the temperament styles described as irascible and impulsive in undercontrolled children at the age of 3 are predictive of involvement in health-risk behaviors at the age of 21.

Our results are mostly in line with Vaughn, Bost and van ljzendoorn's (2008) assumptions that temperament and attachment are independent variables of development that meaningfully contribute to a large range of intrapersonal and interpersonal developmental patterns, both as direct effects and as outcomes of their interaction. Most research on sensation seeking has analyzed its predictor role in risky behavior in adolescents.

Demonstrating the usefulness of attachment theory to explain individual differences in sensation seeking and consequent risky behavior tendency is, in our opinion, an important step to rethink the position that conceives sensation seeking as a stable trait (Lynne-Landsman et al., 2011). Because sensation seeking is one of the main predictors of adolescent risky and problem behaviors that are difficult to change, prevention programs should be targeted to predict and mediate such behaviors.

The possibility of considering sensation seeking as associated to the quality of internal working models, leads to design treatments for adolescents in which the new symbolization of the other may become the medium to abandon an egocentric vision of satisfaction of emotional needs. In this sense, it can be assumed that the work with these individuals may also treat the theme of the theater or the space in which to stage their own emotions. In this sense, the treatment would aim to underline the importance of the relationships within the mental field in which the sensations take on a meaning, and simultaneously breaking the scheme in which the emotional excitement is almost exclusively linked to a kind of self-centered position. In a psychopathological perspective, the perfect prototype of the sensation seeker is the antisocial personality, unable to put off the need to experience pleasure, even when it means ignoring and trampling rules and rights of others. It is for individuals who lack the capacity for empathy, in which the operating model of the other is seen as incapable of meeting the emotional needs or even as threatening. A treatment for adolescents in which the search for sensations reached worrying levels in terms of prediction of dangerous behavior, can, according to the results of this study, also be based on the transformation of the internal working model of others.

\section{References}

Agrawal, A., \& Lynskey, M. T. (2008). Are there genetic influences on addiction: evidence from family, adoption, and twin studies. Addiction, 103, 1069-1081

Allen, J. P., Hauser, S. T., \& Borman-Spurrell, E. (1996). Attachment theory as a framework for understanding sequelae of severe adolescent psychopathology: An 11-year follow-up study. Journal of Consulting and Clinical Psychology, 64, 254-263.

Armsden, G. C., \& Greenberg, M. T. (1987). The inventory of parent and peer attachment: Relationships to well-being in adolescence. Journal of Youth and Adolescence, 16, 427-454.

Baiocco R., Laghi F., D'Alessio M. (2009). Decision-Making Style Among Adolescents: Relationship with Sensation Seeking and Locus of Control. Journal of Adolescence, 32, 4, 963-976

Baldwin, M. W., Keelan, J. P., Fehr, B., Enns, V., \& Koh-Rangarajoo, E. (1996). Social-cognitive conceptualization of attachment working models: availability and accessibility effects. Journal of Personality and Social Psychology, 71, 94-109.

Barnea, Z., Teichman, M., \& Rahav, G. (1992). Personality, cognitive, and interpersonal factors in adolescent substance use: a longitudinal test of an integrative model. Journal of Youth and Adolescence, 21, 187-201.

Baron, R.M., \& Kenny, D.A. (1986). The moderator-mediator variable distinction in social psychological research: Conceptual, strategic, 
and statistical considerations. Journal of Personality and Social Psychology, 51, 1173-1182.

Bartholomew, K., \& Horowitz, L. M. (1991). Attachment styles among young adults: A test of a four category model. Journal of Personality and Social Psychology, 61, 226-244.

Bates, J. E. (1987). Temperament in infancy. In J. D. Osofsky (Ed.), Handbook of infant development. New York: Wiley

Belsky, J., \& Rovine, M. (1987). Temperament and attachment security in the strange situation: An empirical rapprochement. Child Development, 58, 787-795.

Buss, A. \& Plomin, R. (1984). Temperament: Early developing personality traits. Hillsdale, NJ: Erlbaum

Cacioppo, M., Pace, U., \& Zappulla, C. (2013). Parental psychological control, quality of family context and life satisfaction among Italian adolescents. Child Indicators Research, 6, 179-191.

Caspi, A., Begg, D., Dickson, N., Harrington, H., Langley, J., Moffitt, T. E., \& Silva, P. A. (1997). Personality differences predict healthrisk behaviors in young adulthood: Evidence from a longitudinal study. Journal of Personality and Social Psychology, 73, 10521063.

Dadds, M. R., \& Salmon, K. (2003). Punishment insensitivity and parenting: temperament and learning as interacting risks for antisocial behavior. Clinical Child and Family Psychology Review, 6(2), 69-86.

Eisenberg, N., Losoya, S., Fabes, R. A., Guthrie, I. K., Reiser, M., Murphy, B., et al. (2001). Parental socialization of children's dysregulated expression of emotion and externalizing problems. Journal of Family Psychology, 15, 183-205.

Ernst, M., Pine, D. S., \& Hardin, M. (2006). Triadic model of the neurobiology of motivated behavior in adolescence. Psychological Medicine, 36(3), 299-312

Eurispes (2012). Rapporto Nazionale sulla Condizione dell'Infanzia e dell'Adolescenza (National report on infancy and adolescence). XIII ed. Rome

Evans, D. E., \& Rothbart, M. K. (2007). Developing a model for adult temperament. Journal of Research in Personality, 41, 868-888.

Galeazzi, A., D'Incerti, L., \& Franceschina, E. (2003). Sensation seeking Scale VI: Standardizzazione Italiana per Giovani dai 14 ai 20 anni. TPM, 10, 131-140

Guzzo, G., Lo Cascio, V., \& Pace, U. (2013). The role of individual and relational characteristics on alcohol consumption among Italian adolescents: a discriminant function analysis. Child Indicators Research, 6, 605-618.

Harden, K., Quinn P.D., \& Tucker-Drob, E.M. (2012). Genetically influenced change in sensation seeking drives the rise of delinquent behavior during adolescence. Developmental Science, 15, 150-163.

Jeammet, P. (2008). Pour nos ados, soyons adultes. Editions Odile Jacob, Paris.

Kochanska, G., \& Aksan, N. (2006). Children's conscience and self-regulation. Journal of Personality, 74(6), 1587-1617.

Laghi, F. , Baiocco, R., Lonigro, A., Baumgartner, E. (2013). Exploring the relationship between identity status development and alcohol consumption among Italian adolescents. Journal of Psychology: Interdisciplinary and Applied, 3, 277-292

Laible, D. J., Carlo, G., \& Raffaelli, M. (2000). The differential relations of parent and peer attachment to adolescent adjustment. Journal of Youth and Adolescence, 29, 45-60.

Leadbeater, B. J., Kuperminc, G. P., Blatt, S. J., \& Hertzog, C. (1999). A multivariate model of gender differences in adolescents' internalizing and externalizing problems. Developmental Psychology, 35, 1268-1282.

Lynne-Landsman, S. D., Graber, J. A., Nichols T. R., Botvin, G. J. (2011). Is Sensation Seeking a Stable Trait or Does it Change Over Time? Journal of Youth Adolescence, 40, 48-58.

Pace, U., \& Zappulla, C. (2011). Problem behaviors in adolescence: the opposite role played by insecure attachment and commitment strength. Journal of Child and Family Studies, 20, 854-862.

Pace, U., Cacioppo, M., \& Schimmenti, A. (2012). The moderating role of father's care on the onset of binge eating symptoms among female late adolescents with insecure attachment. Child Psychiatry and Human Development, 43, 282-292.

Pace, U., Schimmenti, A., Zappulla, C., Di Maggio, R. (2013). Psychological variables characterizing different types of adolescent gamblers: a discriminant function analysis. Clinical Neuropsychiatry, 10,6, 253-259.

Pace, U., Zappulla, C., Guzzo, G., Di Maggio, R., Laudani, C., \& Cacioppo, M. (2014). Internet Addiction, Temperament, and the Moderator Role of Family Emotional Involvement. International Journal of Mental Health and Addiction, 12, 52-63

Preacher, K.J., \& Hayes, A.F. (2004). SPSS and SAS procedures for estimating indirect effects in simple mediation models. Behavior Research Methods, Instruments, \& Computers, 36, 717-731.

Prinzie, P., Onghena, P., Hellinckx, W., Grietens, H., Ghesquière, P., \& Colpin, H. (2004). Parent and child personality characteristics as predictors of negative discipline and externalising problem behaviour in children. European Journal of Personality, 18, 73-102.

Putnam, S. P., Ellis, L. K., \& Rothbart, M. K. (2001). The structure of temperament from infancy through adolescence. In A. Eliasz, \& A. Angleitner (Eds.), Advances in research on temperament (pp. 165-182). Lengerich, Germany: Pabst Science Publishers.

Rispoli, K. M., McGoey, K. E., Koziol, N. A., Schreiber, J. B. (2013) The relation of parenting, child temperament, and attachment security in early childhood to social competence at school entry. Journal of School Psychology, 51, 643-658.

Rothbart, M. K. (1986). Longitudinal observation of infant temperament. Developmental Psychology, 22, 356-365.

Rothbart, M. K. (2006). Adult Temperament Questionnaire-Short Form (ATQ-SF). Retrieved January 17, 2013, from http://www.bowdoin.edu/ sputnam/rothbart-temperament

Rothbart,M. K., \& Derryberry, D. (1981). Development of individual differences in temperament. In M. E. Lamb \& A. L. Brown (Eds.), Advances in developmental psychology. Hillsdale: Erlbaum.

Rothbart, M. K., Ahadi, S. A., \& Evans, D. E. (2000). Temperament and personality: origins and outcomes. Journal of Personality and Social Psychology, 78, 122-135. 
Rutter, M. (2007). Psychopathological development across adolescence. Journal of Youth Adolescence, 36, 101-110.

Sarracino, A., Presaghi, F., Degni, S., Innamorati, M. (2011). Sex-specific relationships among attachment security, social values, and sensation seeking in early adolescence: Implications for adolescents'externalizing problem behaviour. Journal of Adolescence, 34, 541-554.

Schimmenti, A., Guglielmucci, F., Barbasio, C., \& Granieri, A. (2012). Attachment disorganization and dissociation in virtual worlds: a study on problematic Internet use among players of online role-playing games. Clinical Neuropsychiatry, 9, 195-202

Schimmenti, A., Passanisi, A., Gervasi, A. M., Manzella, S., \& Famà, F. I. (2013). Insecure Attachment Attitudes in the Onset of Problematic Internet Use Among Late Adolescents. Child Psychiatry and Human Development DOI: 10.1007/s10578-013-0428-0

Schimmenti, A., Passanisi, A., Pace, U., Manzella, S., Di Carlo, G., \& Caretti, V. (2014) The Relationship Between Attachment and Psychopathy: A Study with a Sample of Violent Offenders. Current Psychology DOI: 10.1007/s12144-014-9211-z

Sijtsema, J.J., Veenstra, R., Lindenberg, S., van Roon, A.M., Verhulst, F.C., Ormel, J., \& Riese, H. (2010). Mediation of sensation seeking and behavioral inhibition on the relationship between heart rate and antisocial behavior: the TRAILS study. Journal of the American Academy of Child and Adolescent Psychiatry, 49, 493-502.

Sobel, M.E. (1982). Asymptotic confidence intervals for indirect effects in structural equation models. In S. Leinhardt (Ed.), Sociological methodology 1982 (pp. 290-312). Washington, DC: American Sociological Association.

Somerville, L. H., Jones, R. M., \& Casey, B.J. (2010). A time of change: Behavioral and neural correlates of adolescent sensitivity to appetitive and aversive environmental cues. Brain and Cognition, 72, 124-133

Steinberg, L. (2002). Adolescence. McGraw Hill.

Steinberg, L. (2008). A social neuroscience perspective on adolescent risk-taking. Developmental Review, 28, 78-106.

Vaughn, B. E., Bost, K. E., \& van IJzendoorn, M. H. (2008). Attachment and temperament: additive and interactive influences on behavior, affect, and cognition during infancy and childhood. In J. Cassidy, \& P. R. Shaver (Eds.), Handbook of attachment: Theory, research, and clinical applications (2nd ed.). (pp. 192-216) New York: Guilford.

Vaughn, B. E., Bost, K. K., \& van IJzendoorn, M. H. (2008). Attachment and temperament:

Additive and interactive influences on behavior, affect, and cognition during infancy and childhood. In J. Cassidy \& P. Shaver (Eds.), Handbook of attachment (pp. 192-216), New York: Guilford PressWilkinson, Shete, Spitz, \& Swann, 2011

Zuckerman, M. (2007). Sensation seeking and risky behavior. American Psychological Association, Washington

Zuckerman, M. (1994). Behavioral expressions and biosocial bases of sensation seeking. New York, NY: Cambridge University Press.

Zuckerman, M. (2007). Sensation seeking and risky behavior. Washington, DC: American Psychological Association 